HARDY-RAMANUJAN JOURNAL 36 (2013), 34-42

\title{
I AM FIFTY-FIVE YEARS OLD
}

\author{
K. RAMACHANDRA
}

I wish to report on my experiences till to-day. First I will attempt a brief sketch from 18 August, 1933 to 5 August, 1958, a period of twenty-five years.

I was born on 18 August, 1933 in Mandya town (then famous for Sugar factory) in the house of my maternal uncle (as was the custom in those days). My parents are Mallaraiah and Subbalakshamma. The name Mallaraiah was also the name of one of our fore-fathers who settled in Kanakanahalli ( a few centuries ago and they were fairly rich). My parents (when I was born) were living in a rented outhouse belonging to Krishnaswamy Iyengar in the fourth cross road of Srirampuram. The house was in a big compound full of green sceneries and full of tall trees. I was fond of the garden. I was a little mischievous (My mother tells me that I once fell down into a large storage tub containing water and I was rescued by her). Afterwards they moved to another rented house in the Third cross road of Srirampuram.

It was at this time that they purchased (by the sale proceeds of a golden ornament presented to my mother by my grand parents at her wedding) a site measuring $45^{\prime} \times 30^{\prime}$ in Nagappa Block for rupees 300. It was one of a number of ragi fields converted into legally recognized government sites by its owner Nagappa. Incidentally my grandfather's name was also Nagappa and is not connected with Nagappa the owner of ragi fields. The total price was rupees 300 only which is now-a-days not enough for a small family to live for a month. Soon my parents applied for a loan of Rs. 500/- in Srirampuram Co-operative Society and built a house which in all (including the site) cost them around rupees eight hundred only. However, the loan from the Society had to be paid back in certain monthly installments out of my father's salary which was only Rs. 18/- per month. Out of Rs. 18/- we had to pay the monthly installments and manage the living expenses of a family consisting of my father, mother, myself, my grand-father, my grand-mother, my uncle sometimes but rarely other visitors. It was a house occupying half the portion of the site and the other half of the site in front of the house was available for gardening. (Now the site is fully occupied by buildings and there is practically no space for gardening). The neighbors were (though of different castes) very cooperative and we lived as though we were members 
of the same family. (Before settling down at Bangalore as a clerk in a Textile Mills called Minerva Mills, my father was a School Master at Bhadravathi.)

By the time I was four years old a brother of mine (by name Subrahmanya) was born. A few months later to avoid my mischiefs at home I was admitted (informally) to the Municipal Primary School, Srirampuram (I was permitted to attend the classes by the Head Master Venkatsubbaiah, although I was admitted formally only when I was five years old). My talents were not recognized early. (I was an average student till my eighth standard.)

In the meanwhile (when my mother went to help her sister) I was for three months in the village Theppasandra in the house of my father's co-brother N. Ramaiah. He was a village school master. Sometimes when he used to be absent he used to send me to take care of the first four standards and he would come late. I used to look after his classes. He used to tell my parents that I was an abnormally intelligent boy.

Sometime after returning to Bangalore I came across the first volume of the book Algebra by Hall and Knight which was prescribed for my father for his SSLC. I used to delight myself by solving some of the easy exercises from this book. Soon I was acquainted with binomial theorem, exponential and logarithmic functions introduced in connection with compound interest and annuities. My mother used to teach me (and my neighbour's children) at home about Kannada language and some elementary arithmetic. I was recognized to be an abnormally intelligent boy by her. I fared badly in arithmetic in my lower secondary examination and I thought I would fail in the examination. (My weak points were History and Geography). Luckily I passed (in second class) in 1946. But there was a serious catastrophe. My father passed away when the results of the examination were not yet announced. I was only twelve and I was stunned. We had no income suddenly. My father was earning Rs. 50/- per month (at the time of his death) and this income suddenly stopped! Some philanthropic gentlemen (like M. Shankaranarain) helped me to continue my secondary school (i.e high school) education at Sheshadripuram. Its Head Master was K. Subbanna (who is now no more) a distant relative of ours and he granted me full-freeship. I did not have to pay any fee to the school (and this concession was continued throughout my educational career (i.e. till 1956).

Up to the High School the medium of instruction was Kannada. In the High School I changed over to the English medium of instruction. It was here that my talents came to light through the algebra teacher K. Sreenivasa Murthy (he liked me very much) and the teachers of other subjects. K. Subbanna had arranged for a very good batch of highly competent teachers to teach the subjects. I never felt bored. (Only 
thing was I was not good at History, Geography and Civics). I did not score good marks in these subjects). I passed my SSLC examination in 1949 in first class. Due to efficient teaching my classmate V. T. V. Sharma got the eighth rank. My rank was about 25 (I do not remember).

Side by side during my middle and high school education, I used to attend free Sanskrit education classes at the pathashala in Krishnaswamy temple, tenth cross road, Malleshwaram. I had memorized "Amarakosha volume I" and I was about to start vol. II. I had memorized many shabdas (i.e. declension of nouns and conjugation of many verbs). But I had to give up for some reasons. However, what I learnt from these classes was helpful for me in my later education (I chose Sanskrit as my second language unto my degree classes). Highly traditional teachers used to teach us (one of them was N. K. Sreenivasagopalachar). I remember that during Dhanurmasa (a cold month) Prasadam used to be served in the morning at the Ganesha temple and at Krishnaswamy temple both of which were very near the pathashala. It should be mentioned that the sanskrit education in the pathashala was not a hindrance. On the other hand, it acted as a catalyst. But I had to discontinue.

In the third year of high school education I came to know the solution of the quadratic equation. I could solve the cubic equation myself (Later in my degree classes I was thrilled to know the solution of the quartic equation). In the meanwhile I was encouraged by my brave mother to continue my studies in spite of financial crisis. She raised some loans from our farmers (which was repaid only much later) and pulled on. She had to look after myself and my younger brother. We received some financial support from our acquaintances (our distant relatives) and also I could give private tuition to some students and earn some money. Mention should be made of our distant relative M. Shankarnarain and another acquaintance A. Shankarnarayana Rao. (Later in my honors classes I was helped by C. Bhimasena Rao, father of my class-mate C. Vasudeva Murthy, who gave me a temporary employment in the Race Course Clubs during vacations).

My uncle K. Subbaiah lived in sixth cross road Srirampuram and we used to visit their family frequently. Whenever I went to their house I used to look at the mathematics books of my cousin K. S. Suryanarayana who was senior to me by two years at school (After he started earning, we had no financial problems. He used to send us Rs. 20/- every month until I started earning). I could soon work out some of his problems in mathematics and our people were surprised at this. In my SSLC examination (1949) I got 199 out of 200 in mathematics. 
All this used to give me some pleasure, but financial crisis used to eat me. I thought of applying for a job and I did apply to Minerva Mills (where my father used to work). I was refused a job on the grounds that I was too young. So it was with great financial stress that I completed two years of education (1949-1951) and in the vacation I applied for a job again in Minerva Mills and got a job with the help of S. S. Mavinakurve. Soon the results of my intermediate examination were out. I had passed in first class securing 95 percent marks in mathematics. I was soon given a promotion (again thanks to S. S. Mavinakurve) and I remained as a Clerk in the Time Office during 1951-1952 in Minerva Mills. I enjoyed doing my work and prepared a ready reckoner for calculating the wages of labourers. I saved some amount but only a little during one year of service in the mills. I was hesitating to discontinue the job, but my courageous mother urged me to join the college and continue studies. Once again a hurdle. I had got 95 percent marks in mathematics and I was denied a seat for mathematics honours in the first two lists. My mother somehow got information from one of our relatives that a relative of ours (and close friend of my father) by name K. Subba Rao of Ramanagaram was on the selection committee. My mother went to Ramanagaram and requested him to give me a seat.

So it was that I got my seat with my (late) father's influence. I joined mathematics honours in 1952. I was beginning the career of a mathematician. B. S. Madhava Rao who was in charge of the mathematics department had arranged for a nice team of teachers for us for all the three years. Soon B. S. Madhava Rao became the Principal of the Central College. I would like to mention the names of all our teachers but for the fact that this article would become too lengthy. I was strongly under the influence of T. S. Nanjundaiah and B. Seetharama Shastry. A curious incident regarding my revered teacher (Assistant Professor) M. H. Habibullah should be mentioned here. I wanted to get a signature (of a Gazetted Officer) for my application form for fullfreeship and I went to him for a signature. He looked at the entries in the form and cried out "you are very poor. Please accept my help" and he handed out a ten rupees note to me, which I accepted with gratitude.

Coming back to mathematics, I used to spend my spare time in the public library which was near the college in Cubbon Park. It was in this library that I came across (with great luck) Hardy's book S. Ramanujan. It was the most thrilling experience of my life to read through the pages of this book. Even to-day its familiarity has made me worship the book all the more. One great relief during the third year of my honors course was that I stood first in the second year examination and hence got a total scholarship of Rs. 120/-. I was also given a prize for my article 'Vinodaganitha' 
in Kannada. Suffice to say that I completed the Honours degree course with the blessings of my teachers. I passed in first class (securing second rank) in 1955.

Hereafter I joined the masters degree course at the instance of my cousin K. S. Suryanarayana who gave me a help of Rs 20/- per month. In masters degree classes I had to study modern mathematics which I did not like. The only things I liked were rigid dynamics and hydrodynamics taught by P. H. Nagappa. Masters degree course was only for one year. I got the second rank here also and passed the masters degree examination in 1956 in first class (I thought I would fail in the examination and even thought of withdrawing and when I approached S. V. K. Hegde our teacher he told me that Dr. Vaidyanathaswamy had in fact liked my answers in the examination and there was no need to withdraw).

Thus I was by 1956 an unemployed youth. Luckily I did not have to wait for long for a job. During 1956-1958 I was in uncomfortable employments. Of course my colleagues respected me and I had a great satisfaction. I wrote up an article "Mathematician's Eureka" and took part in the 45th session of the Indian Science Congress (1958). I spoke on "Summation of certain series involving $H_{n}=1+\frac{1}{2}+\cdots+\frac{1}{n}$." Professor B. S. Madhava Rao was the president of the Science Congress. It was during these two years that I could read Jacobian Elliptic functions and Whittaker and Watson's book Modern Analysis. I also acquainted myself with H. S. Vandiver's report on Kummer's work on Fermat's Last Theorem and also with Dyson's work on the approximation of algebraic numbers by rational numbers. All the time Professor B. S. Madhava Rao took a keen interest in my work and studies. I wrote up two small notes, one of which was published in Mathematics Student. Its title was "Applications of Fermat's theorem". Another was published in the Journal of the London Mathematical Society. Its title was "A note on the integer solutions of Mordell's equation." Both these papers were typed by Professor Madhava Rao who took a keen interest in me. I have to mention yet another incident. When I was about to take up an employment I told Dr. T. S. Nanjundaiah that I wanted to pursue mathematics as a hobby and I asked him a list of books that would help me in my study. He was very pleased and suggested Ramanujan by G. H. Hardy, Introduction to the theory of Numbers by G. H. Hardy and E. M. Wright, and Introduction to Modern Prime Number Theory by E. Estermann. I bought all these books and studied them.

It was during this two years period that I met (late) Dr. C. T. Rajagopal the Director of the Ramanujan Institute in Alagappa Chettiar's house. He allowed me to use the library. I was interested in the cubic Diophantine equation $x^{3}+y^{3}+z^{3}=3$. The problem (by L. J. Mordell) was to show that all its solutions in integers also 
satisfy $x+y+z=3$ (there are only four common solutions). While studying certain Diophantine equations I was led to the following conjecture: 2 is a cubic residue of a prime number of the form $6 n+1$ if and only if $p=a^{2}+27 b^{2}$ for some integers $a$ and $b$. This is an old result due to C. F. Gauss and Vaidyanathaswamy proved this in his new way in the Science Congress which I attended. One day early in 1958 my cousin K. S. Nagaraja Rao pointed out to me an advertisement calling for admission to TIFR. I applied for it and got selected; needless to say that this was because of the interest of Professor B. S. Madhava Rao in me. He seems to have given a nice certificate about me in correspondence with Professor K. Chandrasekharan, the Deputy Director, Mathematics. Nearly around the same time I got married to my maternal cousin K. Saraswathi. (Two months after my marriage I joined TIFR on 5 August, 1958). Professor C. N. Srinivasa Iyengar also encouraged me to join TIFR. Thus from 5.8.1958 it was a new phase for me.

Suffice to say that I was free to study what I wanted, but with a reservation. I had to attend some lectures on Algebra, Topology and Measure Theory and be prepared to face an interview at the end of the first year. This was more of revision of my masters degree syllabus with some extra information like the non-solvability of equations radicals and so on. Some of these topics interested me but my main interests were elsewhere. So while I was prepared for an interview at the end of the first year, I had spent most of my time (nearly more than half the time) in studying with great joy Transcendental Numbers by C. L. Siegel, Distribution of Prime Numbers by A. E. Ingham, Introduction to Modern Prime Number Theory by T. Estermann, Diophantine equations, and approximation of algebraic numbers by rationals and so on. This was a more delightful experience for me. I did this with the following thing in mind. If by some chance I was disqualified in the first year interview then I can take up an employment elsewhere and pursue these subjects as my hobby. Professor K. Chandrasekharan knew of my interests and cancelled the interviews at the end of the first year and promoted our batch as research associates. He had recognized whatever talents we had and he took this step by himself and also on the advice of Professors Raghavan Narasimhan and K. G. Ramanathan.

With the guidance of Professor K. G. Ramanathan I wrote a thesis which was a continuation of the lectures given during (1959-1960) in TIFR by Siegel. My thesis was published in Annals of Mathematics vol. 80 (1964). I got my Ph.D in 1965 from Bombay University and in 1975 I became a Professor at TIFR. Regarding my Annals paper I am thankful to the following mathematicians for expressing their appreciation: A. Baker, F. R. S., K. Chandrasekharan, K. G. Ramanathan, C. L. 
Siegel, A. Selberg, A. Weil, M. Eichler, K. Iwasawa, J. P. Serre, K. Ananda Rao, C. N. Srinivasa Iyengar, B. S. Madhava Rao, S. V. K. Hegde, T. S. Nanjundaiah to mention only a few. Next I got in to the work of A. Baker and published some papers. It was taken up by my student T. N. Shorey who continued it very well. I am very happy to have collaborated with him on some very important problems like "On gaps between numbers with a large prime factor" and with him and R. Tijdeman on "Grimm's problem." T. N. Shorey was asked to quit because of unsatisfactory progress in Algebra, Topology and Measure Theory and I had to fight in the faculty to reverse the quit order. Another collaboration which I remember happily is that of R. Balasubramanian who is now famous for his work on the mean square of $\left|\zeta\left(\frac{1}{2}+i t\right)\right|$, $\Omega$ theorems (jointly with me), and Waring's problem for fourth powers (jointly with J.-M. Deshouillers and F. Dress). He was also issued a quit notice due to similar reasons and I had to fight to reverse the quit order. In both these cases it was painful for me to persuade the faculty which never took me seriously at least in the beginning. I do not want to comment more on such events.

I have five sacred experiences during my mathematical life. (1) I met Professor Ivan Matveevich Vinogradov once in 1971 on his eightieth birthday and a second time in 1981 on his ninetieth birthday in Moscow. On the second occasion I had the opportunity to meet Vinogradov in his house and worship the venerable old mathematician. I treasure this memory (the sacred mathematician is now no more) as a very sacred event of my life. (2) Meeting Professor Carl Ludwig Siegel more than once (I first met him in 1959-1960) in TIFR and again in July, 1974 in Göttingen. When I met him in Göttingen he was speaking to me about his beliefs regarding the generalized Riemann hypothesis. I had been to Professor Deuring's house where I had a nice vegetarian meal in the Indian style. (3) Meeting in 1970-1971 (the number theory year at Princeton, Institute for Advanced Study) many mathematicians like A. Selberg, A. Baker, F. R. S., H. L. Montgomery, A. Weil, F. J. Dyson, F. R. S., H. M. Stark, W. M. Schmidt, C. Hooley, F. R. S., and others. The number theory year was arranged by A. Selberg. (4) My visit to Nottingham in 1978. (This was made possible because of a research grant by Science Research Council, U. K., to Professors A. Baker, C. Hooley and H. Halberstam to invite me to U. K.) It was during this time that I visited the place in Cambridge where Professor G. H. Hardy lived. (Professor A. Baker is living in that apartment for a long time). I am thankful to Professor H. Halberstam for having arranged very nice apartment for me and my family in Nottingham. I had just to have a pleasant walk through a nice park to reach the University. I am also thankful to him for taking me to Woolworth Manor where Sir 
Issac Newton spent his early life. He also took me to various other memorable places. I am thankful to Professor A. Baker for inviting me and my family to Cambridge. He arranged a nice place for us to stay and showed us around Trinity College. It is a famous College where Sir Issac Newton and G. H. Hardy were professors. Professor A. Baker is now a professor in this very College. I was invited for dinner in the College and introduced to many important members. Professor A. Baker also took us to Ely and we enjoyed seeing the holy churches. I visited the famous College at Cardiff and met the members of the school of number theory there. This was arranged by Professors C. Hooley and M. N. Huxley and I am thankful to them. On the whole I was a pilgrim for 3 months in Nottingham and visited U. K. the holy land of Jesus Christ's Principles, the land of Sir Issac Newton and G. H. Hardy. (5) When Professor Paul Erdös visited TIFR, Bombay in 1979 (for three days) he was my guest in the housing colony, Bhaskara 702. We (myself and my family) regard this as a sacred event. He was discussing many problems of mathematics till late in the night and it was really a great experience for me to be with this great mathematician for three days.

After visiting the famous place (Trinity College) where G. H. Hardy and S. Ramanujan were engaged in their epoch-making collaboration on Circle method, I thought of perpetuating the sweet memory of their collaboration. I founded the Hardy-Ramanujan Society and started publishing Hardy-Ramanujan Journal from 1978 December onwards. The objectives of the Society (not yet registered) are nearly the same as that of S. Ramanujan. It has professors A. Baker, F. R. S., and P. Erdös (the founder of the World Academy of Mathematics) as its honorary fellows. I am its founder and president but I must say that I am thankful to them for helping me to build the Society and that the Society owes its founding very much to these mathematicians.

My other mathematical friends who were helpful to me were Professors M. Jutila, T. Meurman, R. Tijdeman, F. Beukers, A. Ivic, D. R. Heath-Brown, M. N. Huxley, C. Hooley, F. R. S., K. F. Roth, F. R. S., W. K. Hayman, F. R. S., H. Halberstam, D. A. Burgess, (Late) A. E. Ingham, F. R. S., M. Nair, P. Bundschuh, Th. Schneider, D. Wolke, E. Heppner, H.-E. Richert, E. A. J. M. Wirsing, W. Schwartz, A. Schinzel, (Late) H. Hasse, I. Katai, V. T. Sós, G. Halász, S. G. Révész, J. Pintz, E. Szemerdi, A. Sárközy, A. Bá log, Y. Motohashi, T. Tatuzawa, S. Kanemitsu, A. Fujii, (Late) L. K. Hua, Wang Yuan, Pan-Cheng-Dong, S.-T. Lou, Ming-Chit-Liu, P. Shiu, A. A. Karatsuba, A. I. Vinogradov, A. B. Shidlowsky, N. I. Feldman, A. Malyshev, 
(Late) Yu. V. Linnik, A. F. Lavrik, G. Wüstholz, R. Apery, M. Waldschmidt, J.M. Deshouillers, F. Dress, W. M. Schmidt, H. Maier, B. C. Berndt, H. Iwaniec, C. J. Mozzochi, E. Bombieri, S. D. Chowla, D. Brownawell, D. W. Masser, H. L. Montgomery, C. Pomerance, J. L. Hafner, F. J. Dyson, F. R. S., G. A. Kolesnik, G. V. Chudnovsky, P. X. Gallagher, S. Graham, C. Spiro, J. H. Muller, J. Pitman, (Late) K. Mahler, F. R. S., A. J. van-der-Poorten, J. H. Loxton, M. Ram Murty, V. Kumar Murty, M. V. Subbarao, P. Ribenboim, J. M. De Koninck, C. Levesque and others. My indian mathematical friends (outside TIFR) interested in classical number theory and classical analysis and who have helped me are Professors R. P. Bambah, (Late) H. Gupta, V. C. Dumir, Madhu Raka, R. J. Hans-Gill, (Late) D. Suryanarayana, R. Sitaramachandra Rao, (Late) Minaketan Das, K. S. Padmanabhan, M. S. Rangachari, R. Balasubramanian, Alladi Krishnaswamy, G. J. Babu, (Late) C. T. Rajagopal and others. There are also others like the nobel Laureate S. Chandrasekhar who have taken interest in the Society.

One of the rare events in my life was to have met the wife of (Late) S. Ramanujan, F. R. S., namely Smt. Janakiammal from whom I learnt many facts about Ramanujan. I regard S. Ramanujan as my guru and to meet his wife was a great event of my life (she was worshipping the photo of Ramanujan when I met her). There are other events namely when I visited Ramanujan Institute in Alagappa Chettiar's house with C. T. Rajagopal as its Director. Another rare event of my life was the farewell ceremony which was arranged to their students by Professors B. S. Madhava Rao and C. N. Srinivasa Iyengar. It was really very moving and I broke down.

Thank you for your kind listening.

K. Ramachandra 